\title{
Risk management in landfills. A public health perspective
}

\author{
B. Rani-Borges \\ J.M.P. Vieira \\ University of Minho, Braga - Portugal
}

\begin{abstract}
Currently, sanitary landfill is an appropriate option for disposal of waste, mainly because it is a technology with little aggressive environmental impact and associated to low costs and simple operation. However, the deficit in best practices in solid waste management is recognized in scientific literature as the cause of adverse effects on the environment and public health. Since landfill has a relevant social, economic and environmental impact as a sanitary urban infrastructure, new control approach based on public health and environmental integrity should be developed in order to prevent diseases propagation and negative environmental impacts. This research work presents a novel concept of landfill safety plan, using similar approach as the well established water safety plan methodology, structured on risk assessment and risk management throughout the waste collection and disposal system.
\end{abstract}

\section{INTRODUCTION}

The continuous increase on urbanization and people standards of life has a high influence on waste collection and disposal policies. The accumulation of waste has become a real urban problem, causing serious impacts on public health and environmental integrity. Currently, landfill as an appropriate technological option for municipal solid waste (MSW) disposal, is used especially because it has little environmental impact, with small costs and simple operation (Cossu, 2013). However, the deficit in best practices of solid waste management systems, especially the absence of a public health protection policy and environmental pollution control are recognized in the scientific literature as the cause of adverse effects associated to MSW management (Giusti, 2009).

Quality assurance of the MSW management system is an essential element of public health policies since human health can be affected by solid waste in different ways (Karak et al. 2012). The negative aspects presented by sanitary landfills are caused by inadequate waste disposal and unstructured management systems which can cause contamination of water, air and soil. Moreover bad practices contribute to the appearance of vectors and epidemiological agents which involve various impacts on the environment and human health (Brown et al. 2011). Thus, grows the need to seek improvements to the technology for MSW collection and disposal (Pereira \& Maia, 2012).

A special issue to be considered in landfills operation is the emission of pollutants (liquid and gaseous: leachate and biogas) originated from degradation of the organic matter fraction of MSW. The environmental impacts of these emissions essentially depends on the characteristics of the residues brought to the landfill, the geological features of the site, the applied technology and other conditions (Gomes, 2009).

Today, more and more people are concerned about the risks to health and the environment associated to landfills and are increasingly demanding definitive solutions not just only for the present but also for the future generations. Also according to the World Health Organization (WHO) it is necessary to identify and to assess the health risks to prevent illness and injury. 
Hence, it is recommended to implement an integrated risk management strategy covering all the steps off MSW management system with special focus on landfills.

\section{BACKGROUND}

\subsection{Public health risks related to landfills}

The disposal of MSW in landfills is an adequate technologic solution when best practices and operational standards are followed. However this solution can cause environmental concerns (mainly related to waste biodegradation) and public health. The pollution can reach different levels of the environment and, consequently, affect the public health in different ways (Butt et al. 2008).

Health impacts can be associated to all the steps of MSW management system by direct or indirect contact (Forastiere et al. 2011). Human exposure to toxic chemicals that exist in landfills can occur through inhalation of pollutants in the air, by contact with contaminated soil and water, leachate, or micro and macro-vectors like birds, insects, rodents.

Several authors (EA, 2011, Elliott et al. 2001, Giusti, 2009, Jarup et al. 2002, Palmiotto et al. 2014, Perez et al. 2006) have investigated the negative impacts on human health associated with landfills by describing the potential causes of disease according to exposure routes and substances formed during and after the process of MSW biodegradation as shown in Figure 1.

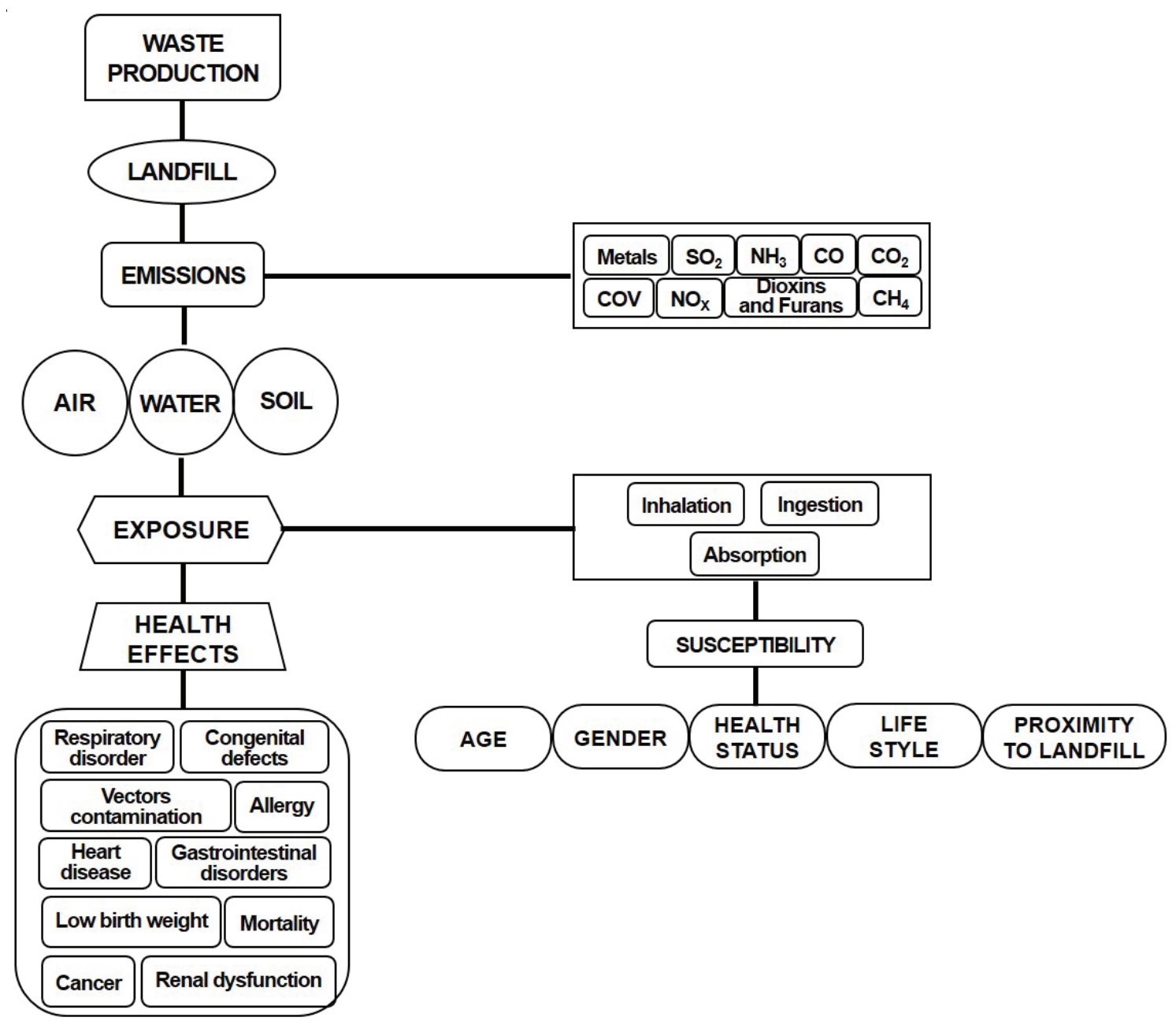

Figure 1. Diagramatic scheme of solid waste emissions and exposure routes 
During the process of treatment and disposal of MSW in landfills, the environment can be found in many situations of potential risks, including impacts on the quality of air, soil and groundwater. Although there are no ways to completely avoid the negative environmental impacts, risk assessment and risk management can significantly reduce them so as to allow the maintenance of environmental health (Butt et al. 2014) and consequently protecting the public health quality.

Most of the environmental problems related to landfills include, among other problems: contribution to the greenhouse effect, resulting from emissions of $\mathrm{CH}_{4}$ and $\mathrm{CO}_{2}$; generation of several toxic substances and volatile organic compounds; odor; noise; depletion of the ozone layer; damage to vegetation; contamination of air, water and soil with leachate and heavy metals; affect the animals health and contributes to the proliferation of insects and rodents (Cossu, 2013, Forastiere et al. 2011, Giusti, 2009).

With the development of science and technology it is possible to control or even eliminate certain hazards and undesirable hazardous events, such as those triggered due to the operation of the landfill, by applying risk management approach (Proag \& Proag, 2014).

\subsection{Risk management}

Risk management is a systematic process consisting of a set of analytical steps and activities required for control of hazard and hazardous events for a specific system or project (Aven, 2009, Irimia-Dieguez et al. 2014). Risks and hazardous events evaluated by this tool can be positive or negative, since the risk management study any situation that influences the project in question, regardless of the nature and may also be identified inside or outside of organization's environment (PWC, 2008).

Although it is a tool that needs improvements (Serpella et al. 2014), is widely used in different areas of science and industry because it is essential for good project management since it is applied to identify, analyze and define strategies to deal with the risks (Dey, 2012). Besides it providing a good foundation for decision-making that help to reduce the expected impacts. The risk management process is indispensably multidisciplinary, bringing together knowledge and data as necessary for a good risk assessment, including socio-economic and environmental data (Travis \& Bates, 2014).

This process consists of several steps, which are outlined in Figure 2. Enforcement of sequence of steps that make up the risk management allows decision making according to the risks and likely hazardous events, in order to guarantee only the occurrence of acceptable events (Tohidi, 2011). What is possible because of the prioritization and measures to eliminate or mitigate risks that reduce the magnitude of hazardous events (Struik et al. 2015).

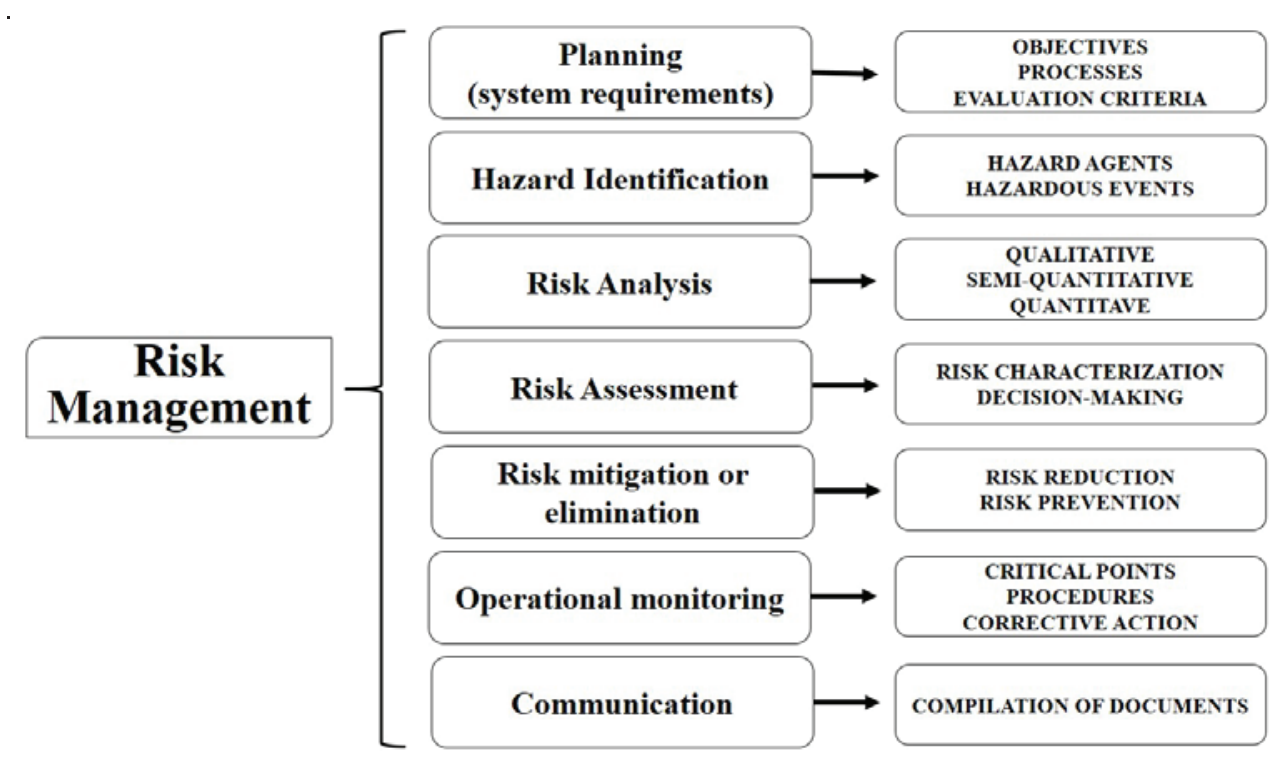

Figure 2. Steps of the risk management process 


\subsection{Risk management in landfills}

The adoption of methodologies for risk assessment and risk management must comply with the environmental and economic requirements and consequently reflect on safety and ensuring the quality of management and treatment of solid waste service. The result of analyzes shall indicate the performance of risk management and may thus be a measure of the evolution of the damage suffered by the public health and the environment (Butt et al. 2014).

Risk analysis for landfill is based on characterization of the sources of danger, and the landfill risks must be established from emissions for several toxic and carcinogenic substances and their amplitude varies according to the exposure levels. That is, the risks are increased according to inhalation of gases or particles, water intake and food contaminated with leachate, direct contact with contaminated soil and other situations (Davoli et al. 2010). The hazard identification process depends on understanding all the steps and system operation of MSW management, which makes it possible to analyze all potential biological, physical, chemical and radiological hazards that may be associated (Forastiere et al. 2011).

Besides pollution, the risk analysis must include less impacting issues such as odor, risks of failures in engineering processes and characterization of chemical and biological components in the system (Pollard et al. 2006).

The impacts on human health and environment integrity by the components of landfill could not be validated because the results of the studies are considered insufficient due to the large variables that result in the absence of concrete evidence (Giusti, 2009, Palmiotto et al. 2014, Porta et al. 2009). Therefore it is essential to carry out future research work that include a risk management for the disposal process of MWS and that may elucidate the risks present on this system and any eventual consequences as well as notify the population affected by this technological solution.

\section{LANDFILL SAFETY PLAN}

The World Health Organization Guidelines for Drinking-water Quality (WHO, 2004, WHO, 2011), introduced a new concept of risk assessment and risk management in drinking-water systems through water safety plans (WSP). This integrated and preventive methodology starts from the establishment of health-based targets and provides a systematic and comprehensive risk assessment and risk management approach for consistently ensuring the safety of a drinking-water supply system from the catchment to the consumer. Generous bibliography has been published on this subject and this is a well-established methodology around the world (Vieira \& Morais, 2005; Vieira, 2011).

A keynote lecture at the 2nd International Africa Sustainable Waste Management Conference (Vieira, 2014) recommended the development of a concept of landfill safety plan for a similar purpose. This novel concept should comprise three essential steps: (i) system and exposure assessment, referring to mapping the system, assessing the risks along the waste collection and disposal system, and the exposure level of different vulnerable groups; (ii) operational monitoring establishing control measures for previously identified and prioritized hazards and exposures at control points; (iii) management plans describing actions and control measures to be taken during normal operation or extreme and incident conditions. This concept of landfill safety plan must be built on the structure of a water safety plan, but also with significant differences due to the specificity nature of a waste collection and disposal system.

\section{CONCLUSION}

Human activities generate big quantities of solid waste being its management in urban scale difficult due to the implications in public health and environment. Science and technology developments permit the implementation of different methods for collection and disposal of MSW. The use of landfilling technology for waste disposal presents some risks to public health and environmental integrity although it presents a broad variety of benefits at the social, economic and environmental dimensions. 
Hazards and hazardous events associated to landfills can cause severe damages in human health and in environment integrity, through the contamination of air, water and soil and contribute to the proliferation of pathogenic agents and consequently trigger serious consequences for exposed populations. These aspects show the necessity to develop a new approach to MSW management systems based on risk assessment and risk management methodologies in order to identifying hazards and hazardous events, assessing and prioritizing risks and applying control measures to eliminate or mitigate those risks and promote the values of public health and environmental protection.

Based on a successful approach of risk management for drinking-water supply systems applying the water safety plan methodology it is recommended to develop a novel concept of landfill safety plan for a similar purpose. This new approach must consider the specific nature of a waste collection and disposal system.

\section{ACKNOLEDGEMENT}

Financial support from CAPES scholarship and Science Without Borders program Bex Process 12993-13-1.

\section{REFERENCES}

Aven, T. (2009). Risk Analysis and Management. Basic Concepts and Principles. Reliability \& Risk Analysis: Theory \& Applications, pp. 57-73.

Brown, C., Milke, M., \& Seville, E. (2011). Disaster waste management: A review article. Waste Management, pp. 1085-1098.

Butt, T.E., Gouda, H.M., Balochd, M.I., Paul, P., Javadi, A.A., \& Alam, A. (2014). Literature review of baseline study for risk analysis - The landfill. Environment International, pp. 149-162.

Butt, T.E., Lockley, E., \& Oduyemi, K.O. (2008). Risk Assessment Of Landfill Disposal Sites - State Of The Art. Waste Management, pp. 952-964.

Cossu, R. (2013). Groundwater contamination from landfill leachate: when appearances are deceiving! Waste Management, pp. 1793-1794.

Davoli, E., Fattore, E., Paiano, V., Colombo, A., Palmiotto, M., Rossi, A.N., . . Fanelli, R. (2010). Waste Management Health Risk Assessment: A case Study of a Solid. Waste Management, 1608-1613.

Dey, P.K. (2012). Project risk management using multiple criteria decision-making technique and decision tree analysis: a case study of Indian oil refinery. Production Planning \& Control: The Management of Operations, pp. 903-921.

EA. (2011). Environment Agency. Additional guidance for H4 odour management. Bristol.

Elliott, P., Briggs, D., Morris, S., Hoogh, C., Hurt, C., \& Jensen, T.K. (2001). Literature review of baseline study for risk analysis - The landfill leachate case. BMJ, 363-368.

Forastiere, F., Badaloni, C., Hoogh, K., Kraus, M.K., Martuzzi, M., Mitis, F., . . Briggs, D. (2011). Health Impact Assessment of Waste Management Facilities in Three European Countries. Environmental Health.

Giusti, L. (2009). A review of waste management practices and their impact on human health. Waste Management, 2227-2239.

Gomes, L.P. (2009). Estudos de caracterização e tratabilidade de lixiviados de aterros sanitários para as condições brasileiras. Rio de Janeiro: ABES/PROSAB.

Irimia-Diéguez, A.I., Sanchez-Cazorla, A., \& Alfalla-Luque, R. (2014). Risk Management in Megaprojects. Procedia - Social and Behavioral Sciences, pp. 407-416.

Jarup, L., Briggs, D., Hoogh, C., Morris, S., Hurt, C., Lewin, A., . . Elliott, P. (2002). Cancer risks in populations living near landfill sites in Great Britain. British Journal of Cancer, 1732-1736.

Karak, T., Bhagat, R.M., \& Bhattacharyya, P. (2012). Municipal Solid Waste Generation, Composition, and Management: The World Scenario. Critical Reviews in Environmental Science and Technology, pp. 1509-1630.

Palmiotto, M., Fatore, E., Paiano, V., Celeste, G., Colombo, A., \& Davoli, E. (2014). Influence of a municipal solid waste landfill in the surrounding environment: Toxicological risk and odor nuisance effects. Environment International, 16-24.

Pereira, A.L., \& Maia, K.M. (2012). Contribuição da gestão de resíduos sólidos e educação ambiental na durabilidade de aterros sanitários. Sinapse Múltipla, pp. 68-80.

Perez, H.R., Frank, A.L., \& Zimmerman, N.J. (2006). Health Effects Associated With Organic Dust Exposure During the Handling of Municipal Solid Waste. Indoor and Built Environment, 207-212. 
Pollard, S.J., Smith, R., Longhurst, P.J., Eduljee, G.H., \& Hall, D. (2006). Recent developments in the application of risk analysis to waste technologies. Environment International, 1010-1020.

Porta, D., Milani, S., Lazzarino, A.I., Perucci, C.A., \& Forastiere, F. (2009). Systematic review of epidemiological studies on health effects associated with management of solid waste. Environmental Health.

Proag, S.L., \& Proag, V. (2014). A framework for risk assessment. Procedia Economics and Finance, pp. 206-213.

PWC. (2008). A Pratical Guide for Risk Assessment - How principles-based risk assessment enables organizations to take the right risks. Price WaterhouseCoopers.

Serpella, A.F., Ferrada, X., Howarda, R., \& Rubio, L. (2014). Risk management in construction projects: a knowledge-based approach. Procedia - Social and Behavioral Sciences, pp. 653-662.

Struik, L.C., Jong, S.V., Shoubridge, J., Pearce, L.D., \& Dercole, F. (2015). Risk-based Land-use Guide:. Geological Survey of Canada.

Tohidi, H. (2011). The Role of Risk Management in IT systems of organizations. Procedia Computer Science, pp. 881-887.

Travis, W.R., \& Bates, B. (2014). What is climate risk management? - Editorial. Climate Risk Management, pp. 1-4.

Vieira, J.M.P., Morais, C. M. (2005). Planos de Segurança da Água para Consumo Humano (Drinking Water Safety Plans). IRAR Edition, ISBN: 972-99354-5-9, p. 173. Lisbon, Portugal.

Vieira, J.M.P. (2011). A Strategic Approach for Water Safety Plans Implementation in Portugal. Journal of Water and Health, IWA Publishing, 09.1, pp. 107-116.

Vieira, J.M.P. (2014). Landfill Safety Plan. A Methodology to Guarantee Safe Waste Management. 2nd International Africa Sustainable Waste Management Conference. Luanda, Angola.

WHO (2004). Guidelines for Drinking-water, third edition. Geneva: World Health Organization.

WHO (2011). Guidelines for Drinking-water, fourth edition. Geneva: World Health Organization. 